\title{
International
}

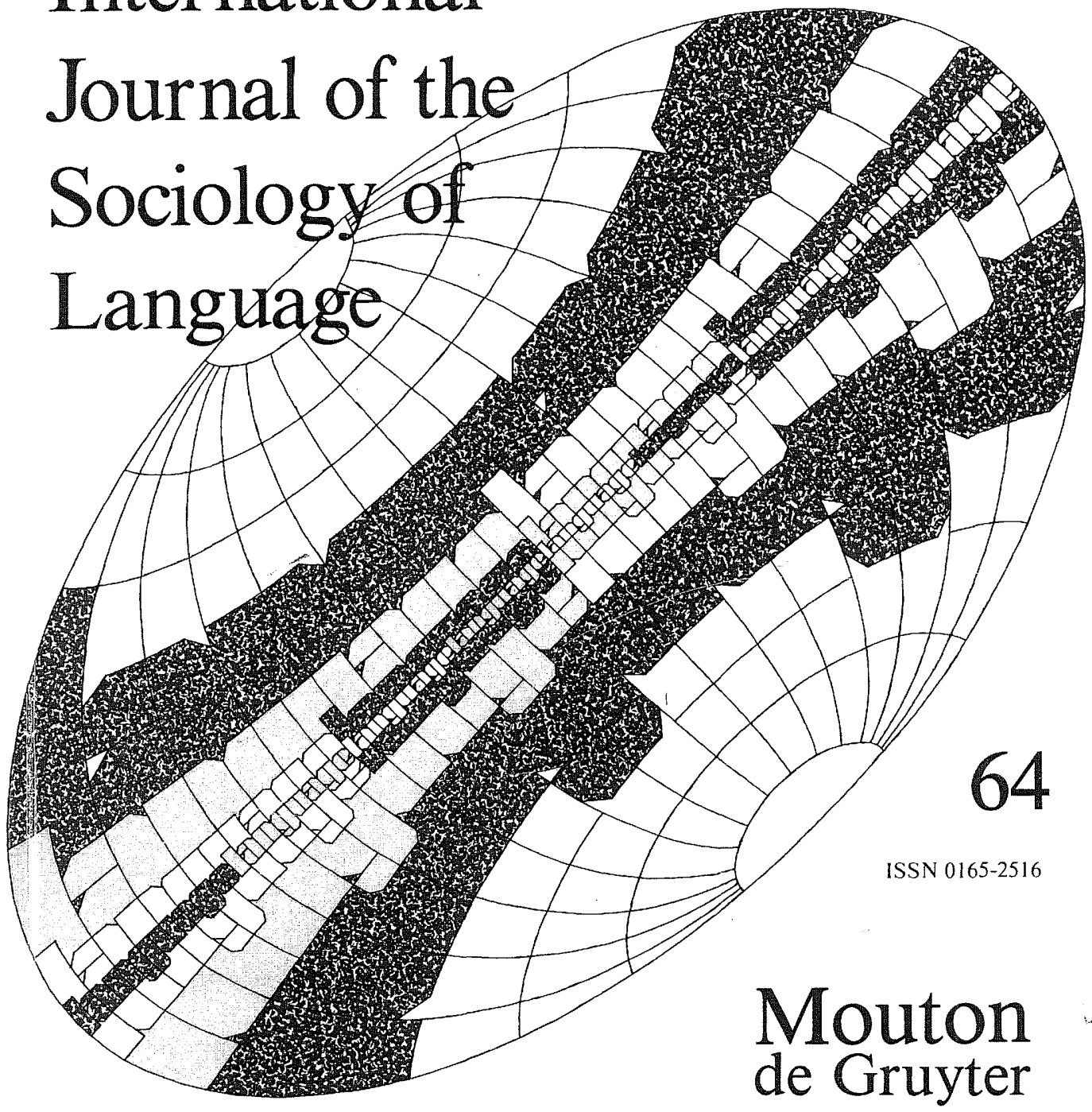

The Sociology of Frisian

DURK GORTER, Issue Editor

Durk Gorter

Pieter H. van der Plank

Lammert G. Jansma and

Gjalt $H$. Jelsma

Klaas J. van Dijk

Gerard van Rijn and Cees Sieben

Theun Meestringa
Koen Zondag

Tony Feitsma, Els van der Geest,

Frits van der Kuip, and Irénke Meekma

Krine Boelens

Alastair G. H. Walker and Ommo Wilts

Jim Smith

Bouke Oldenhof 


\section{Variations and development in Frisian sandhi phenomena}

TONY FEITSMA, ELS VAN DER GEEST, FRITS VAN DER KUIP, and IRÉNKE MEEKMA

\section{Introduction}

Where a dominant and a subordinate language are spoken in one area, the current view is that the subordinate language will be influenced by the dominant language. Because Friesland has a bilingual situation, in which Dutch is the dominant language in more formal domains, one might expect Frisian to change under the influence of Dutch. In such a process, women, the upper classes, and younger people are supposed to change first. We therefore frame the hypothesis that these groups will generally show Dutch linguistic forms to a greater extent.

\section{Social and linguistic variables}

\section{Social variables}

Our inquiry 'Changes in pronunciation of Frisian under the influence of Dutch' focuses on the pronunciation of a number of sandhi phenomena in the Frisian and the Dutch of native speakers of Frisian. We expect the pronunciation of Frisian and Dutch of the individual informants to run parallel as regards the extent of its Frisian character.

The project contains two elements that are rather unusual in sociolinguistic research:

1. Our informants are divided into groups of three belonging to the same family, either as grandfather, father, and son or as grandmother, mother, and daughter (in order to keep other factors in the comparison between the generations maximally constant).

2. The informants are interviewed in Frisian and in Dutch by a Frisian native speaker and a Dutch native speaker respectively (in order to keep the circumstances of the interviews as natural as possible). 
The 25 families of informants consist of Frisian-speaking autochthones in the heart of the Frisian countryside. ${ }^{2}$ They are divided into five groups of five families each: male nonfarmers with higher education, male nonfarmers with lower education, female nonfarmers with lower education, male farmers, and 'female farmers' (= wives and daughters of farmers).

The interviews were tape-recorded between the autumn of 1982 and the autumn of 1984. The informants of the oldest generation were born between 1897 and 1917, those of the middle generation between 1926 and 1946, and those of the youngest generation between 1952 and 1969. Moreover, the informants were asked to answer questions about their language background, attitudes, etc.

We made a distinction between higher and lower education and not between higher and lower social class, because social class is at first sight not a very relevant feature for the language of the countryside (see Hoppenbrouwers 1982: 9). In our study, higher education means a completed secondary education at the former Dutch ULO or the present HAVO or higher (or for some of the youngest generation, attendance at such a school).

Pietersen (1969: 102) recorded that farmers in Friesland have a rather positive attitude to the Frisian language. Jul Nielsen (1984:21) states that in the Danish countryside, especially elderly persons who are or have been engaged in farm work still use the dialects in their classical form as everyday speech. For these reasons we also included farming families in our inquiry and formulated the hypothesis that nonfarmers would have a less Frisian pronunciation than farmers. Within the group of farmers we did not make a distinction between higher and lower education.

To begin with, only the texts of four 'male families' from three groups, $3 \times 4$ families, have been transcribed. For this article, only the informal texts of these 36 persons were used.

\section{Linguistic variables}

The focus of the study is on some largely unconscious pronunciation phenomena in external sandhi in Frisian and Dutch. We make a distinction between a Frisian pronunciation $(+\mathrm{Fr}[$ isian $])$ and a non-Frisian or not distinctly Frisian pronunication ( $-\mathrm{Fr}[$ isian] or $\pm \mathrm{Fr}$ [isian] respectively).

a. Nasalization. Vowel $(\neq$ schwa) + word-final $n$ may become a nasal vowel. This phenomenon is studied in the following environments: before the continuants $1, \mathrm{r}, \mathrm{s}, \mathrm{z}$ (voiced alveopalatal fricative), and $\mathrm{j}$ (palatal semivowel).

$\mathrm{Vn} \rightarrow \widetilde{\mathrm{V}} /-\#$ \# $1, \mathrm{r}, \mathrm{s}, \mathrm{z}, \mathrm{j}$ 
Nasalization or complete disappearance of nasality ( $\widetilde{\mathrm{V}}$ or $\mathrm{V})$ is $+\mathrm{Fr}$.

Non-nasalization and retention of $n(\mathrm{Vn})$ is -Fr. Examples:

(Frisian) . b $\widetilde{z e} /$ bi ze vs. bin ze 'are they'

(Dutch) kã ze/ ka ze vs. kan ze 'can she'

b. Assimilation of $-s$. Word-final $s$ may become $\mathrm{z}, \mathrm{d}$ or $\emptyset$. This phenomenon is studied with the words is, as, als in the following environments: before vowel (V) and before the voiced consonants $\mathrm{j}, \mathrm{v}, \mathrm{l}, \mathrm{r}, \mathrm{m}, \mathrm{n}, \mathrm{d}$.

$\mathrm{s} \rightarrow\left\{\begin{array}{l}\mathrm{Z} \\ \mathrm{d} \\ \emptyset\end{array}\right\} /-\#$ - $\mathrm{V}, \mathrm{j}, \mathrm{v}, \mathrm{l}, \mathrm{r}, \mathrm{m}, \mathrm{n}, \mathrm{d}$

Assimilation is + Fr. Nonasssimilation is - Fr. Examples:

(Frisian) iz er / id er vs. is er 'is he'

(Frisian) iz myn / i myn vs. is myn 'is my'

(Dutch) iz naast / i naast vs. is naast 'is next to'

c. Assimilation (deletion) of $d-$. Word-initial $d$ in the article (Frisian/Dutch de) $[=$ the $]$ can be deleted. This phenomenon is studied in the following environments: after prepositions ending in $m, n, p$ (Frisian/Dutch: om, $y n / i n$, tsjin, oan/aan, fan/van, op ) [= about, in, against, on, from, upon] .

$\mathrm{de} \rightarrow \mathrm{e} / \mathrm{om}, \mathrm{yn}$, in, tsjin, oan, aan, fan, van, op \#\# -

Assimilation is $+\mathrm{Fr}$. Nonassimilation (de) or assimilation from de to te is -Fr. Examples:

(Frisian) oppe/ynne vs. ob de/ op te / yn de 'upon the/ in the' (Dutch) oppe/inne vs. ob de/ op te/ in de 'upon the/ in the'

d. Syllabification or nasalization of -en. Word-final en following a consonant or vowel may become a syllabified nasal $(n, m, p)$ or a nasalized vowel (nasal $\widetilde{e}$ ). This phenomenon is studied in the following environments: before the continuants $s, z$ (voiced alveopalatal fricative), $x$ (voiceless velar fricative), $\mathrm{f}, \mathrm{v}, 1, \mathrm{r}, \mathrm{j}$ (palatal semivowel), and w (bilabial semivowel).

en $\rightarrow\left\{\begin{array}{c}n \\ 1 \\ m \\ p \\ p \\ \widetilde{\mathrm{e}}\end{array}\right\} /\left\{\begin{array}{l}\mathrm{C} \\ \mathrm{V}\end{array}\right\}-\# \#$ continuant consonant $(\neq \mathrm{h})$

Syllabification and nasalization are +Fr. Nonsyllabification and non-nasaliza- 
tion (prononunciation: en/em/en) is \pm Fr. Replacement with $e$ is - Fr. or possibly + Fr. (see remark below). Examples:

(Frisian) tossn fol / tossẽ fol vs. tossen fol ( \pm Fr.) / tosse fol (-Fr.) (Dutch) tassn vol/ tassẽ vol vs. tassen vol ( \pm Fr.)/ tasse vol (-Fr.) (Dutch) ze koomm van/ ze koomẽ van $( \pm$ Fr. $)$ / ze koome van (possibly + Fr.) 'bags full' and 'they come from' respectively.

e. Syllabification of -en. Word-final en following a consonant or vowel may become a syllabified nasal $(\mathrm{n}, \mathrm{m}, \mathrm{n})$. This phenomenon is studied in the following environments: before a pause, $h$, a vowel, or the non-continuants $d$, $\mathrm{t}, \mathrm{b}, \mathrm{p}, \mathrm{g}, \mathrm{k}, \mathrm{n}, \mathrm{m}$.

$$
\text { en } \rightarrow\left\{\begin{array}{c}
n \\
m \\
m \\
1 \\
r
\end{array}\right\} /\left\{\begin{array}{l}
\mathrm{C} \\
\mathrm{V}
\end{array}\right\},-\# \#\left\{\begin{array}{c}
\text { non-cont } \\
\mathrm{V} \\
\text { pause } \\
\mathrm{h}
\end{array}\right\}
$$

Syllabification is + Fr. Nonsyllabification (pronunciation: en/em/en) is \pm Fr. Replacement with $e$ is - Fr. or possibly + Fr. (see remark below). Examples:

(Frisian) tossn dêr vs. tossen dêr $( \pm$ Fr. $) /$ tosse dêr $(-F r$.) (Dutch) tassṇ daar vs. tassen daar ( \pm Fr. $) /$ tasse daar ( - Fr.) (Dutch) ze koomm er vs. ze koomen er $( \pm$ Fr. $) /$ ze koome er (possibly + Fr.) 'bags there' and 'they come there' respectively.

Remark on $\mathrm{d}$ and e. The pronunciation $e$ in Dutch does not always have to be - Fr.; $e$ may run parallel to the verb-final $e$ of the present tense plural in Frisian (Dutch: jully loope/koome = Frisian: jim rinne/komme) [you walk/ come] ( $e$ is used for schwa in the sections on syllabification). This so-called Frisian morphological $e$ in Dutch we consider as a possibly Frisian pronunciation. We will look at the relative frequencies of syllabification (nasalization under $\mathrm{d}$ included) both with and without Frisian morphological $e$. From now on the term 'syllabification' will be used for syllabification/nasalization of $-e n(\mathrm{~d})$ and syllabification of $-e n(\mathrm{e})$.

\section{Optionality and quasi-categorial $85+$ rule and $15-$ rule}

Under the usual definition the rules formulated above would be categorial if they applied in $100 \%$ of the instances. Using this definition would mean that there would be almost no categorial rules left in our material. However, it is still useful to distinguish between rules that apply very regularly and those that apply less frequently. For that reason we distinguish the following: 
- quasi-categorial $85+$ rules (with relative frequencies of $85 \%$ or more);

- optional rules in a narrower sense (with relative frequencies between $15 \%$ and $85 \%$ );

- quasi-categorial 15- rules (with relative frequencies of $15 \%$ or less). ${ }^{3}$

\section{Results}

\section{Hypotheses}

According to our hypotheses as accounted for above,

a. the pronunciation of Frisian and Dutch would run parallel to each other regarding the + Frisian frequencies scored by the different generations;

b. the youngest generation would have a less Frisian pronunciation than the oldest;

c. more highly educated people would have a less Frisian pronunciation than those with lower education;

d. nonfarmers would have a less Frisian pronunciation than farmers.

In our analysis of variance ${ }^{4}$ we introduce the variable 'societal group', which covers the two variables 'education' and 'farmer/nonfarmer'. The values of this new variable are nonfarmer with higher education (NFH), nonfarmer with lower education (NFL) and farmer (F) (see Figure 1).

\section{Analysis of variance}

Looking at our data, we observe that three phenomena show a significant difference between the languages: assimilation of $s(\mathrm{~F}(1,9)=8.05, \mathrm{p}<$ $0.05)$, assimilation of $d(\mathrm{~F}(1,9)=71.25, \mathrm{p}<0.01)$, and syllabification $(\mathrm{F}(1,9)=309.57, \mathrm{p}<0.01)$. If, with respect to syllabification, we count the so-called Frisian morphological $e$ as + Fr., the difference between the two languages becomes smaller but is still found to be highly significant $(F(1,9)$ $=188.04, \mathrm{p}<0.01$ ).

Our speakers do not nasalize significantly less in Dutch than they do in Frisian $(F(1,9)=4,36, p>0.05)$. In both languages the nasalization scores are high (greater than $85 \%$, Figures $2 \mathrm{a}$ and $2 \mathrm{e}$ ). Taking into account these two facts, one could assume nasalization to be a rather unconscious and unnoticed phenomenon. In Frisian there is no significant difference between either the three generations or the three societal groups we distinguish. In Dutch, however, the variable societal group turns out to be highly significant $(F(2,9)=$ 9.04, $\mathrm{p}<0.01$; for mean scores see Figure 1 ). The + Fr. score of the NFH 


\begin{tabular}{|c|c|c|c|c|c|c|c|c|c|c|c|c|c|c|c|c|c|c|c|}
\hline & Frisian & Dutch & $\mathrm{s}$ & Frisia & & & $\mathrm{s}$ & Dutcl & & & $\mathrm{s}^{\circ}$ & Frisia & & & $s$ & \multicolumn{3}{|l|}{$\frac{\mathrm{NFH}}{\text { Dutch }}$} & $\mathrm{s}$ \\
\hline $\begin{array}{l}\text { NAS } \\
\text { ASS s } \\
\text { ASS d } \\
\text { SYL/NAS }\end{array}$ & $\frac{\frac{96.3}{91.5}}{83.3}$ & $\begin{array}{c}\frac{93.3}{85.8} \\
54.7 \\
32.1 \\
(53.2)\end{array}$ & $\begin{array}{l}- \\
+ \\
++ \\
++ \\
++\end{array}$ & $\begin{array}{l}\frac{94.7}{93.2} \\
79.3 \\
78.1\end{array}$ & $\begin{array}{l}\frac{96.7}{92.4} \\
84.1 \\
78.3\end{array}$ & $\frac{\frac{97.5}{89.0}}{\frac{86.5}{83.4}}$ & $\begin{array}{l}- \\
- \\
- \\
+\end{array}$ & $\begin{array}{r}\frac{91.4}{87.8} \\
49.9 \\
43.8 \\
(61.8\end{array}$ & $\begin{array}{l}\frac{91.7}{83.3} \\
52.7 \\
27.3 \\
50.0\end{array}$ & $\begin{array}{l}\frac{96.8}{86.4} \\
\frac{61.4}{25.0} \\
47.8)\end{array}$ & $\begin{array}{l}+ \\
- \\
- \\
+ \\
+\end{array}$ & $\begin{array}{l}\frac{93.7}{89.5} \\
74.4 \\
78.7\end{array}$ & $\begin{array}{l}\frac{97.7}{91.8} \\
83.5 \\
81.0\end{array}$ & $\frac{\frac{97.5}{93.3}}{\frac{92.1}{80.2}}$ & $\mid \begin{array}{l}- \\
- \\
++ \\
-\end{array}$ & $\begin{array}{r}\frac{88.3}{79.6} \\
37.5 \\
23.7 \\
(44.8\end{array}$ & $\begin{array}{l}\frac{96.0}{89.2} \\
\frac{67.0}{34.4} \\
59.7\end{array}$ & $\begin{array}{l}\frac{95.7}{88.7} \\
\frac{59.5}{38.0} \\
55.0)\end{array}$ & $\begin{array}{l}++ \\
- \\
+ \\
- \\
-\end{array}$ \\
\hline & & & $\begin{array}{c}\uparrow \\
\text { SYI } \\
\text { lang } \\
\end{array}$ & $\begin{array}{l}\text { NAS: } \\
++\end{array}$ & $\begin{array}{l}\text { intera } \\
\text { nd gene } \\
(++)\end{array}$ & $\begin{array}{l}\text { ction b } \\
\text { ration }\end{array}$ & et & & & & $\uparrow$ & & & & & & & & \\
\hline
\end{tabular}

The total number of cases in which a + Fr. rule could apply, is for

NAS (nasalization) Frisian 1772, Dutch 1531;

ASS s (assimilation of $-s$ ) Frisian 1599, Dutch 1832;

ASS d (assimilation of d-) Frisian 1096, Dutch 827;

SYL/NAS (syllabification/nasalization of -en) Frisian 5493, Dutch 8267.

() Relative frequency + Fr., Frisian morphological schwa included.

Underlined $85+$ or $15-$ (quasi-categorial).

$\mathrm{s}$ significance $(++\mathrm{p}<0.01 ;+\mathrm{p}<0.05 ;-$ not significant $)$.

I/II/III: oldest/middle/youngest generation.

NFH/NFL/F: nonfarmer with higher education/nonfarmer with lower education/farmer.

Figure 1. Means (in \%) of the relative frequencies of individual $+F r$. scores (in \%) 
is much lower than that of the other two groups. There is also a significant difference between generations $(F(2,9)=5.88, p<0.05)$. The youngest generation has a higher + Fr. score than the older.

Another rather unconscious and unnoticed phenomenon may be the assimilation of $s$ (Figures $2 \mathrm{~b}$ and $2 \mathrm{f}$ ). Assimilation of $s$ exceeds $85 \%+\mathrm{Fr}$. in both Frisian and Dutch, whereas the + Fr. score of the youngest generation is somewhat lower than that of the oldest one, in both languages (Figure 1). As noticed before, there is a significant difference between the two languages. Whether the development of assimilation of $s$ in Frisian and Dutch runs parallel cannot be determined from our analysis. Analysis of variance does not demonstrate a significant difference between either generations or societal groups in Frisian and Dutch.

Next we turn to assimilation of $d$ (Figures $2 \mathrm{c}$ and $2 \mathrm{~g}$ ). The difference between the two languages is apparent and highly significant $(F(1,9)=71.25$, $\mathrm{p}<0.01)$. Generation does not seem to make a significant difference in either language. As can be seen in Figure $2 \mathrm{~g}$, the NFH have a much lower + Fr. score in Dutch than the NFL $(F(2,9)=4.54, p<0.05)$. In Frisian the difference is largest between the NFH and the farmers $(F(2,9)=7.54, p<$ 0.01 ).

Finally we will look at the most conscious and stigmatized phenomenon, syllabification (Figures $2 \mathrm{~d}$ and $2 \mathrm{~h}$ ). It is worth noticing that the youngest generation has a higher $+F r$. score in Frisian $(F(2,9)=3.57$, p. $<0.05)$ and a lower + Fr. score in Dutch (without Fr. morph. $e$ : $\mathrm{F}(2,9)=6.96, \mathrm{p}<0.05$; with Fr. morph. $e: F(2,9)=5.22, p<0.05)$ than the older ones. In other words, whereas in Frisian syllabification is increasing, in Dutch syllabification is decreasing. A highly significant interaction effect is found between generation and language (without Fr. morph. $e: \mathrm{F}(2,18)=10.67, \mathrm{p}<0.01$; with Fr. morph. $e: \mathrm{F}(2,18)=9.69, \mathrm{p}<0.01)$. Another remarkable fact seems to be the much lower + Fr. score in the Dutch of the NFH group. This difference, however, appears not to be significant (without Fr. morph. $e: \mathrm{F}(2,9)=1.85$, $\mathrm{p}>0.05$; with Fr. morph. $e: \mathrm{F}(2,9)=2.88, \mathrm{p}>0.05)$.

\section{Discussion}

\section{Summary of the results}

The youngest generation almost always has a + Fr. score equal to or higher than that of the oldest generation in Frisian and in Dutch. With respect to syllabification, the ways of Dutch and Frisian part, Dutch becoming more and more de-frisianized, Frisian becoming gradually purer. On the whole the 
a. NASALIZATION

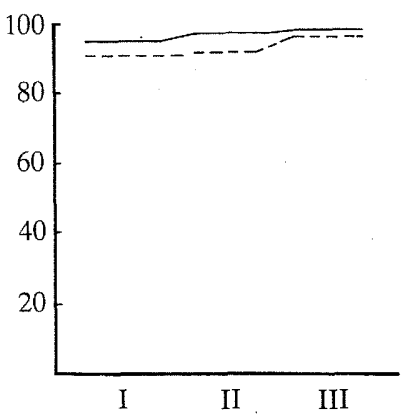

e. NASALIZATION

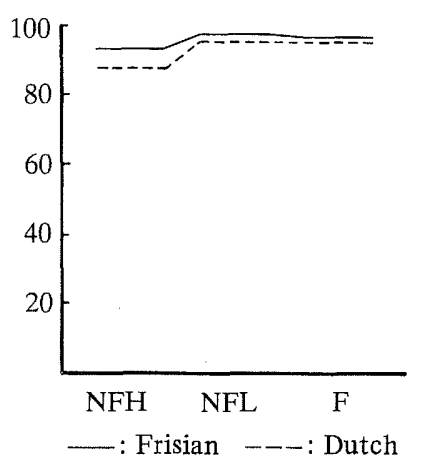

b. ASSIMILATION of $s$

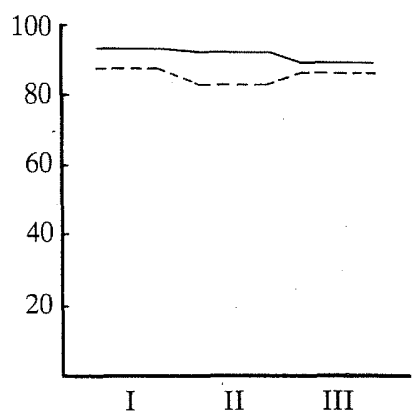

f. ASSIMILATION of $s$

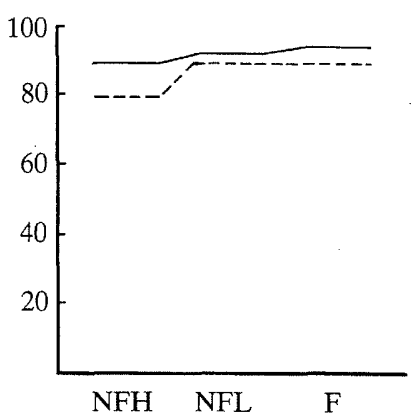

c. ASSIMILATION of $d$

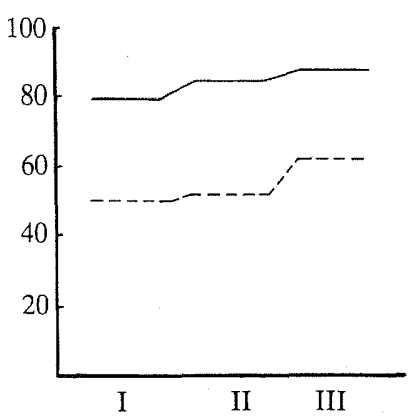

g. ASSIMILATION of $d$

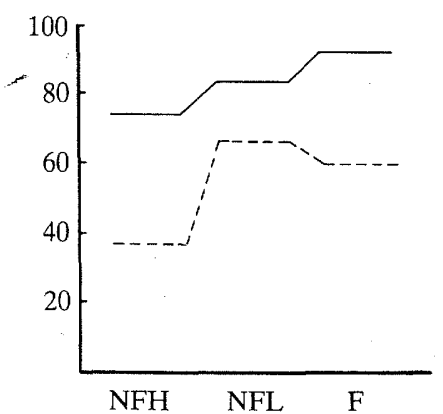

d. SYLLABIFICATION/

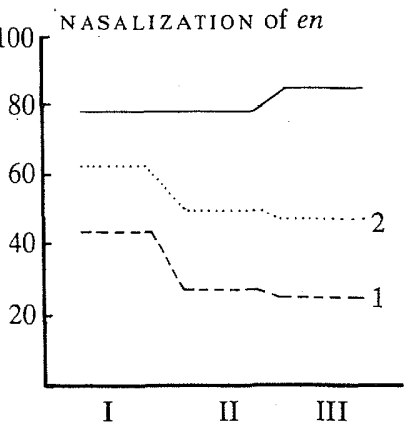

h. SYLLABIFICATION/

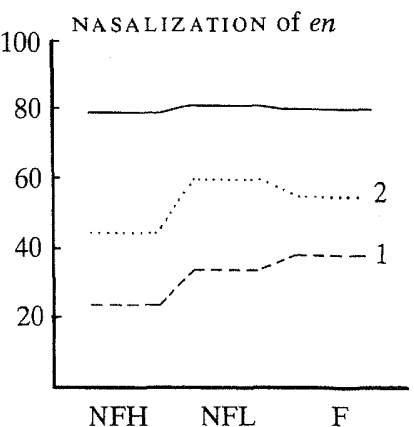

1: relative frequency + Fr. without Frisian morphological $e$; ...... 2: relative frequency $+\mathrm{Fr}$. with Frisian morphological $e$.

I/II/III: oldest/youngest generation.

NFH/NFL/F: nonfarmer with higher education/nonfarmer with lower education/farmer.

Figure 2. Frisian pronunciation in Frisian and Dutch (in \%), according to generation (a-d) and according to societal group (e-h) 
NFH group has a lower +Fr. score than the NFL group and the group of farmers. The fact that the pronunciation of the youngest generation is so much more Frisian than that of the oldest one and, moreover, that syllabification even shows an increasing difference between Frisian and Dutch because of an opposite development in Frisian and Dutch is in conflict with our hypothesis that the language of the youngest generation would be most affected by Dutch, with Frisian and Dutch running parallel in such a process of 'Dutchifying'.

\section{Pronunciation of the youngest generation}

The literature shows that it is not unusual for the youngest generation not to behave in conformity with our hypotheses.

First of all we must consider that pronunciation occupies a special position within the field of linguistic variation. Hudson (1980: 48) tentatively distinguishes between syntax as the marker of cohesion in society, vocabulary as a marker of divisions in society, and pronunciation as the reflection of the permanent social group with which the speaker identifies.

Wolfram (1969: 204-206) registers that in Detroit negro speech there is less conscious awareness of the phonological variables than of socially diagnostic grammatical variants, and several preadolescent and teenage informants reveal scores which are quite typically working class (because of factors like peer identity, reaction to adult norms, etc.?).

Labov (1972: 257) also sees the youngest generation, not specifically as regards pronunciation, as the best vernacular speakers, especially

those between the ages of 9 and 18. It is well known that in most cities peergroup membership reaches a peak at the ages of 15 to $16[\ldots]$; as the young adult is detached from the teenage hang-out group he inevitably acquires a greater ability to shift towards the standard language and more occasions to do so.

Labov deals with variation in 'modern urban sociolects' and not with 'changes in rural dialects', but Hoppenbrouwers (1982: 96-97) does regard the influence of the peer group as 'a useful principle of explanation', also for the rural dialects and regiolects he deals with. Labov is also talking about a more limited group of the youngest generation than in our definition. In our material the differences between the six informants under 18 and the six informants over 20 do not seem to be very great. If there is any difference, the tendency seems to be for those over 20 to have a little more $+F$ r. in 
Frisian and a little less + Fr. in Dutch than those under 18. So Labov's explanation does not really apply to our results.

\section{Internal structure of the speech community}

We distinguished three generations and three societal groups, but we did not use 'social class'. Perhaps we should go even further and in the scope of this study aim our efforts more at the internal structure and the preexisting groups in the 'community' (after Hymes's definition, as used by Milroy 1980: 15: 'a local unit, characterised for its members by common locality and primary interaction'). Because of its 'strong territorial basis' (Milroy 1980: 14) our population certainly satisfies the criterion of 'common locality' (maybe somewhat arbitrarily delimited). It is more difficult to assess the extent of 'primary interaction'. We did not examine this systematically, but some answers to our questionnaire provide us with information about the ties of the individual informants to the area, and the contents of the interviews as well as the conversations before and after often showed that several informants, even from different villages, knew each other rather well. Moreover, our group of farmers undoubtedly shows some characteristics of a preexisting group in the community.

As a corollary of the above, the present inquiry into the language usage of some social groups has to be completed with further study of the position of the various persons in the speech community in connection with their linguistic usage. There are perhaps other factors than those arising from the division we made which account just as well or even better for the differences in linguistic usage.

Milroy systematically studies the relationship between heavy usage of vernacular speech and the internal structure of the group using that vernacular. She objects to the social factors that are traditionally connected with differences in linguistic usage: 'the heaviest users of the vernacular are not necessarily old people, nor are conservative dialects giving way to the spread of standard English'; she believes it 'to be a tendency for low-status people in communities to use vernaculars as symbols of local loyalty'. On the other hand, she points out that in general, it seems that socially and geographically mobile individuals lack certain local loyalties and the characteristically dense patterns of interaction within a limited area (Milroy 1980: 6, 7, 18, 16).

For our inquiry this could mean that our autochthonous informants with presumably 'dense multiplex networks' in their rural Frisian community would be relatively closely tied to the Frisian identity and hence preserve a relatively Frisian pronunciation. These loyalties and the Frisian pronunciation connected to them could be less strong for Frisians who are socially and 
geographically more mobile. A comparison with more mobile people could therefore be a proper object of a subsequent inquiry.

There is another factor in the Frisian language community as a whole that without doubt has generally added to the loyalty to the Frisian language. That is the Frisian Language Movement, which has been very important for the use of Frisian in books, theater, and songs from the 19th century onward. In our century a further aim of the Frisian Movement is to promote the use of the Frisian language in education and in higher domains in general. This language movement is doubtless also supportive of local loyalties and the informal usage of the Frisian vernacular in the smaller-scale Frisian speech communities. This does not mean that these loyalties imply an explicit connection with the Frisian Movement and its ideology. Milroy (1980: 18) states that low-prestige ethnic and status groups everywhere perceive their language or dialect as a powerful symbol of group identity, [...] whether or not speakers attribute a positive value to them when questioned directly.'

It is, by the way, not at all certain that the Frisian-minded adherents of the Frisian Movement have the most Frisian pronunciation; it is perfectly possible that they may try to 'beautify' the Frisian pronunciation and in this way make their pronunciation more Dutch.

\section{The pronunciation of Frisian}

The language consciousness and self-confidence stimulated by the Frisian Language Movement are without any doubt among the factors which maintain the perception of Frisian as a distinct entity and hence also maintain a real separation between the Frisian spoken language and Dutch. This might thwart the development of a direct continuum between Frisian and Dutch (see Trudgill 1983: 190-191). In other words, Frisian is, in this view, relatively focused (on its own norms), as opposed to the development of a predominating continuum from dialect to Dutch, such as Hoppenbrouwers $(1982,1983)$ registers for other rural areas in the Netherlands. Hoppenbrouwers calls such relatively diffuse continua 'regiolects'. The terms 'focused' and 'diffuse' were suggested by Le Page (Milroy 1982: 141; Hudson 1980: 15).

Accordingly, for our informants, Frisian belongs to the kernel competence (Seuren 1980: 49); the +Fr. scores of the various informants in Frisian consequently show a smaller dispersion than in Dutch; in Dutch the differences between the individual scores are often greater.

Moreover, the Frisian pronunciation of Frisian is well preserved by our informants, especially by the youngest generation. The syllabification scores of the youngest generation show the greatest difference between Frisian and Dutch, and that too is an indication of the separate position of Frisian. 
The NFH group, on the contrary, always has the lowest + Fr. scores, and that could point at a Dutch direction for the future.

\section{The pronunciation of Dutch}

Along with the distinct Frisian vernacular, there exists a continuum between Frisian-colored Dutch and the 'standard' pronunciation of Dutch. During the Dutch interviews several informants of the oldest generation from the NFL group and from the group of farmers appeared to have trouble speaking Dutch. The younger generations showed more fluency in this language. Parallel to this we see in our results a less Frisian pronunciation of Dutch with respect to syllabification. On the whole, however, the youngest generation nearly always shows the highest + Fr. score, in both Frisian and Dutch, whereas the NFH group always shows the lowest $+F r$. score, especially in Dutch.

At first sight, the difference in the pronunciation of Dutch between the decreasing use of syllabification of $e n$ and the quasi-categorial or increasing use of nasalization and assimilation of $s$ and $d$ is somewhat similar to certain features of the regional standard used by speakers under 20 in Burträsk. While these 'show almost total absence of dialect variants of certain features, they at the same time almost totally avoid standard variants of other features' (Thelander 1982: 72). Thelander believes the vitality of a dialect variant in present-day Burträsk to be dependent on its greater geographical dispersion in northern Sweden. However, the geographical dispersion of the Frisian features we study does not seem to play a role in the vitality of Frisian pronunciation features in Dutch. Syllabification, characteristic of the northeast Netherlands, is widely known and mimicked as such. It is rather the stigmatization which seems to be the decisive factor with syllabification in the pronunciation of Dutch. This stigmatization, however, does not seem to thwart the increase of syllabification in Frisian, as found in our inquiry, as discussed above.

Perhaps in the future Frisian pronunciation of Dutch, the most distinctly Frisian phenomena will be avoided, like for instance syllabification in some specific environments (see forthcoming publications), whereas less conscious and hence less stigmatized features (for example nasalization) will stay for a longer time (see Hagen 1981: 155-158, 168-173, on primary and secondary dialect features). To a certain extent this would mean a development similar to that of Urban Frisian, which developed some centuries ago as an interlanguage between Frisian and Dutch, in which the most distinctly Frisian diphthongs and consonant clusters have disappeared but the Frisian articulation has been preserved (Fokkema 1937: 75-76).

In our day, interlanguages of this type seem to be developing again. Thelander (1982) deals with such a regional standard between the Burträsk 
dialect and the-Swedish standard language. Developments like these are to be found in the regiolects Hoppenbrouwers $(1982,1983)$ describes for different Dutch dialect areas (see Hagen 1981: 85-86).

Probably, however, we must compare the Dutch material from our inquiry with the dialect-colored Dutch pronunciation of the Dutch standard language in other rural areas, because the pronunciation may or may not belong to the standard language, and in Britain, for example, 'many people use a regional accent but standard dialect' (Hudson 1980: 33, 44; see Trudgill 1983: 187-190).

\section{Concluding remarks}

Comparing our informants with the groups which the Taal yn Fryslân survey (Gorter et al. 1984) distinguishes, we see that all our informants are autochthons, country people, and native speakers of Frisian, for whom Frisian is the normal everyday language at home; in other words, our informants belong to those groups that have a relatively positive attitude toward Frisian. Moreover, they are relatively nonmobile. Consequently our informants are not representative of 'the Frisian-speaking Frisians' or of 'the inhabitants of Friesland'.

The inquiry described here is not complete. First of all, the interviews with female informants, which have been recorded but not worked out yet, will have to be studied. Furthermore, the other inquiries mentioned in the preceding sections would be necessary in order to see our results in the right perspective.

Vrije Universiteit, Amsterdam

\section{Notes}

1. This research was supported by the Foundation for Linguistic Research, which is funded by the Netherlands Organization for the Advancement of Pure Research, ZWO.

2. The area is formed by the municipality of Boarnsterhim and a smaller area to the north of it (on 1 January 1984: approximately 20,000 inhabitants and an area of about 20,000 hectares).

3. For the $85+$ score, compare also Hoppenbrouwers (1983).

4. We used the computer program BMDP8V to perform an analysis of variance for a split-plot design with equal cell sizes.

\section{References}

Fokkema, K. (1937). Het Stadsfries. Assen: Van Gorcum. 
Gorter, D., Jelsma, G. H., van der Plank, P. H., and de Vos, K. (1984). Taal yn Fryslân. Undersyk nei taalgedrach en taalhâlding yn Fryslân. Ljouwert: Fryske Akademy.

Hagen, A. (1981). Standaardtaal en dialectsprekende kinderen. Muiderberg: Coutinho.

Hoppenbrouwers, C. A. J. (1982). Language Change: A Study of Phonemic and Analogical Change with Particular Reference to S.E. Dutch Dialects. Meppel: Krips.

- (1983). Het genus in een Brabants regiolect. $T A B U$ 13, 1-25.

Hudson, R. A. (1980). Sociolinguistics. Cambridge: Cambridge University Press.

Jul Nielsen, B. (1984). Bidrag til Vendelbomalets fonologi. Del I Dialekten $i$ Tornby. With an introduction in English. Copenhagen: Akademisk Forlag.

Labov, W. (1972). Language in the Inner City: Studies in the Black English Vernacular. Philadelphia: University of Philadelphia Press.

Milroy, L. (1980). Language and Social Networks. Language in Society 2. Oxford: Blackwell.

- (1982). Social networks and linguistic focusing. In Sociolinguistic Variation in Speech Communities, S. Romaine (ed.), 141-152. London: Arnold.

Pietersen, L. (1969). De Friezen en hun taal: Een onderzoek naar de lees-en spreekgewoonten in Friesland en naar de houding ten aanzien van het Fries. Drachten: Laverman.

Romaine, S. (ed.) (1982). Sociolinguistic Variation in Speech Communities. London: Arnold.

Seuren, P. A. M. (1980). Variabele kompetentie: linguistiek en sociolinguistiek anno 1980. In Handelingen van het 36ste Nederlands filologencongres 1980, Amsterdam: APA-Holland University Press.

Thelander, M. (1982). A qualitative approach to quantitative data. In Sociolinguistic Variation in Speech Communities, S. Romaine (ed.), 65-83. London: Arnold.

Trudgill, P. (1983). On Dialect. Social and Geographical Perspectives. Oxford: Blackwell.

Wolfram, W. A. (1969). A Sociolinguistic Description of Detroit Negro Speech. Washington, DC: Center for Applied Linguistics. 